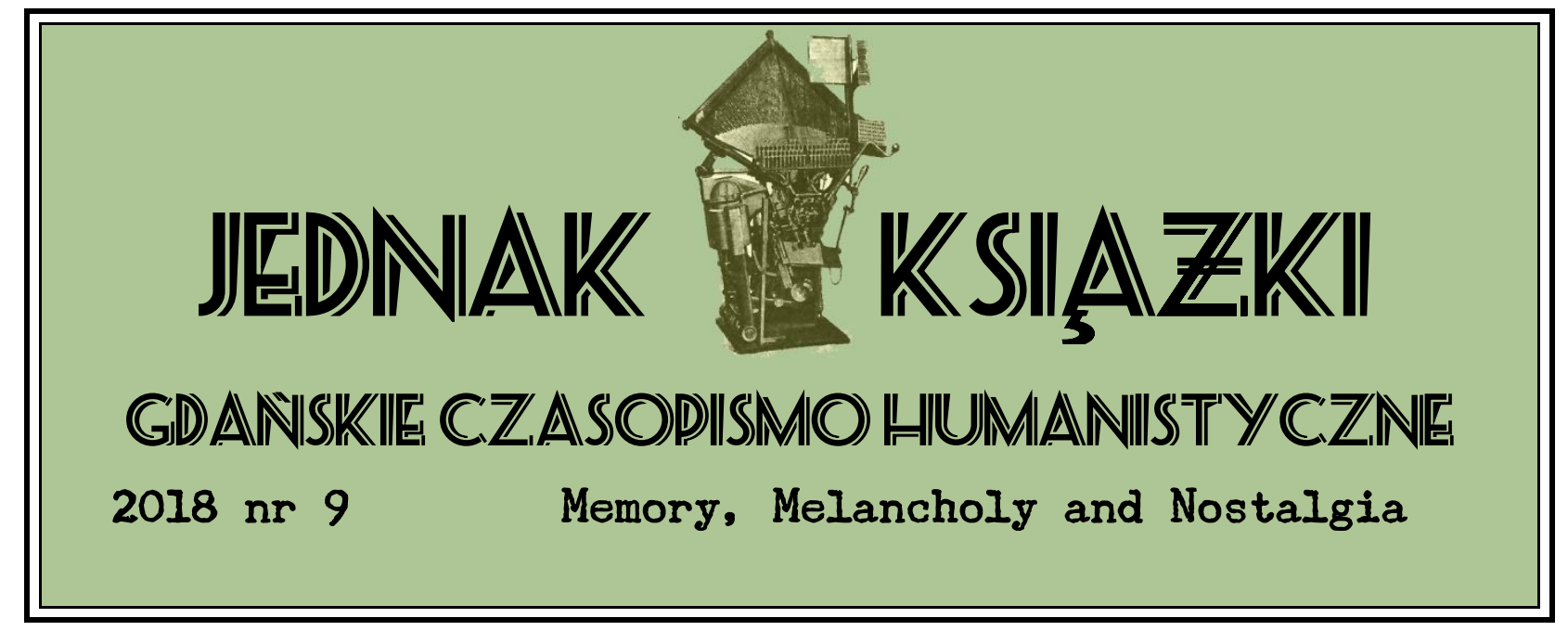

\title{
STUDIESS
}

https://doi.org/10.26881/jk.2018.9.10

\section{“OUR FLAME, THE WILL-O'THE-WISP THAT DANCES \\ IN A FEW EYES, IS SOON TO BE BLOWN OUT AND ALL WILL FADE" - MODERN LITERARY NOSTALGIA AS DEATH MOOD}

\section{NIKLAS SALMOSE}

Linnaeus University in Växjö (Sweden)

Department of Languages

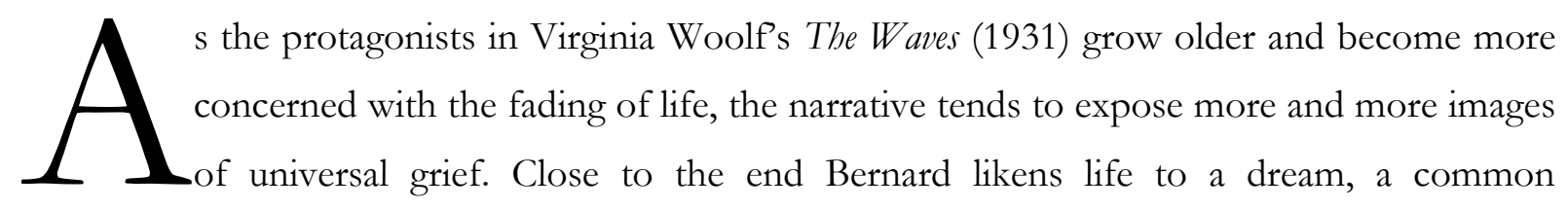
metaphor for the denial of the realities of life, which he brilliantly formulates in the next sentence: "Our flame, the will-o'-the-wisp that dances in a few eyes, is soon to be blown out and all will fade"(Woolf 2000: 155). If Bernard's horror against time seems utterly personal, Louis's cry against the inexorable passage of time anticipates the end of everything: 
'But listen," said Louis, "to the world moving through abysses of infinite space. It roars; the lighted strip of history is past and our kings and queens; we are gone; our civilization; the Nile; and all life. Our separate drops are dissolved; we are extinct, lost in the abysses of time, in the darkness.'(Woolf 2000: 127)

The separate drops that dissolve isolated through the unusual use of the semicolon, is a brilliant image of our brief history in the universe before its end. This, let us call it universal grief (that we shall all face annihilation), is in fact intimately bound to the nostalgic experience. The nostalgic strains against modernity and progress may very well be an indication of the way nostalgia's project of halting time originates in this universal grief that emancipates from teleology. James G. Hart writes that, even though death is not considered part of nostalgia it is nevertheless related "to times recalled by nostalgia, because it is the most complete expression that these golden times are irretrievably lost to us" (Hart 1973: 407). Nostalgic imagery that evokes this sense of meaninglessness or death, and at the same time celebrates life, is not uncommon in literature. Often there is resonance of the astronomical images or temporal indicators that contrasts our personal death with how life goes on without us. More so, death can be envisioned as something peaceful, utopian, a return to the origins of the world or childhood. In this essay I will argue that in order to fully comprehend nostalgia, and literary nostalgia, we must investigate one of its basic mechanisms: how nostalgia is triggered by our universal grief and resistance to death. A second premise is that it is useful to separate between nostalgic emotion, a complex set of emotions that are perceived and reflected upon in a cognitive manner, and nostalgic mood that is a less cognitive and less spatiotemporal form of nostalgia. It is in the latter form that the notion of universal grief has a paramount position. I will start with a definition of nostalgic mood and then move on to discuss literary nostalgia, and its corresponding nostalgic tropes, from the modernist period, and how the particular literary nostalgic mood in modern fiction in fact is a result of our teleological and entropic concerns.

In comparison to nostalgic emotion, nostalgic mood can be regarded as less cognitive, less biographical and thus impersonal, and a more subtle state of mind, which means that we experience sensations rather than perceiving them. These might very well be complex and physical, but the actual chain of emotional and cognitive events, such as nostalgia usually is perceived in cognitive psychology, is incomplete. There will be a motivator of some sort, but in the nostalgic emotion this motivator can be either voluntary or involuntary whereas the motivator in the nostalgic mood is undeniably involuntary. In the nostalgic mood there is more 
of a sense of flow or gradual awareness of a state of affection. The most important difference is the lack of an obvious nostalgia, an object for the nostalgic experience which makes these moods less biographical in the sense that we do not recall a particular, personal event in the past. During a nostalgic emotion we often quite clearly can specify what we are nostalgic about. This appears more diffuse in the event of nostalgic mood, probably due to the lower cognitive aspect of the experience. However, there is great deal of overlap between emotion and mood. The most common definition is that mood usually implies a longer time than an emotion and is of a lower intensity. A typical example is that of feeling fear (emotion) when seeing a dog rapidly approaching and being in a state of anxiety (mood) for a while after the dog has disappeared.

The affective content of the nostalgic mood is very similar to what is gained from the dualism of nostalgic emotions: the bittersweet mixture of joy and sadness with an emphasis on one of them that constitutes whether the mood is positive or negative. This might seem to contrast research that shows that we often speak of mood as being either "good" or "bad" as in being in a good or bad mood. If we connect this to the positive or negative general interpretation of the mood this opinion still seems valid, but what about the two contrasting emotions? One of Robert E. Thayer's main theories about moods is that they are indeed built up of a combination and interaction of two separate moods, what he names energetic and tense moods (Thayer 1989: 110-36). Overtly simplified, the energetic mood (positive/high arousal) tends to activate the person and the tense mood (negative/low arousal) to calm him. The multidimensional arousal model, as presented by Thayer, allows for a complex interaction of these apparent contrasting emotional states. One of Thayer's examples accounts for exactly this: “A continuing state of high anxiety would certainly characterize high arousal, and yet the fatigue and tiredness that usually reflect low arousal states is also found in these cases"(Thayer 1989: 115). Although nostalgia is not an anxiety, it seems probable that we can apply Thayer's model also on that of nostalgic mood.

The dualism of emotions in nostalgia corresponds well with Freud's polarities between life instincts and death instincts as he expresses them in "Beyond the Pleasure Principle" (Freud 1955: 53). The play between pleasure, Eros, and death, Thanatos, harmonizes with the two last phases of the nostalgic reaction. The joyfulness (defeating the irreversibility of time, the idealized or selected memory, the life strengthening aspects of the nostalgia) seems to parallel that of the Freudian pleasure principle. Simultaneously, the return to origins can also be integrated in the death drive. Freud writes, backing his observation with the biological science of the times that "the aim of all life is death" and that "organic life [strives] to restore an earlier state of things" 
(Freud 1955: 38, 36). He continues by quoting Schopenhauer's famous remark that death is the "true result and to that extent the purpose of life" (qtd. in Freud 1955: 50).

The nostalgic dualism between death and life is also observed by Ann C. Colley in Nostalgia and Recollection in Victorian Culture (1998) where she connects it to the myth of Orpheus:

It is as if nostalgia roams between the tenor of death and the vehicle of life. Like Orpheus, nostalgia attempts to recover what darkness imprisons so that it might lead what is lost back towards the light of the living present. Nostalgia charms death with its bitter-sweet melodies [...]. (Colley 1998: 209)

In the nostalgic experience it is the knowledge of our short time, in combination with the strong notion of extinction that initiates the stout sadness of lost time. It can only be regained in our subjective minds, but that is not satisfactory.

The strange sadness of nostalgic mood is also seen in Freud's distinction between mourning and melancholia: mourning is the loss of something real, a person, a place or something equivalent, and it heals in course of time - melancholia is the loss of something abstract and time won't heal it. In a contradictory way, the abstraction of death embraces life in the nostalgic mood experience.

In a strict sense, there are two crucial definitions of nostalgia: one, the nostalgic emotion, has to do with the dichotomy of now and then (and more spatially here and there), and the other, nostalgic mood, is concerned with universal grief, the fear of death and progress. The nostalgic efforts from fiction are all based on either one of these or on a set of variations and combinations of them, but it is where it focuses on universal grief literary nostalgia become less spatiotemporal (as the nostalgic emotion requires) and propels nostalgic moods instead. This section investigates how nostalgic moods fuelled by nostalgia's inherent relation to death operate in modern fiction.

The conventions of modern nostalgic tropes evolve out of the idealized spaces and the nostalgic dichotomies from romantic nostalgic poetry, as Aaron Santesso convincingly displays in his very insightful A Careful Longing: The Poetics and Problems of Nostalgia (2006). The most common tropes are the tropes of idyllic, innocent childhood; the nostalgic childhood tropes, therefore, will then be everything associated with childhood such as children, children's games, and toys. Santesso writes that Schiller argued that children are also associated with nature because 
"children were emblematic of a lost relationship with nature" (Santesso 2006: 70). Nostalgic childhood tropes, then, come to symbolize nature as well.

In addition, several tropes function as a reminder of passing times such as the use of astronomical imagery in some of Dryden's elegies which are associated with "the ideas of decay, collapse, and change [...]" (Santesso 2006: 34) or the potent symbol of the ruin as a metaphor for change. The ruin becomes symptomatic for the time arrow in that everything inevitably will decay and die.

Santesso concludes that " $[\mathrm{m}]$ odern nostalgic tropes might be different-white picket fences rather than village squares-but certain tropes still act as triggers that cause us to engage in nostalgic reflection" (Santesso 2006: 188). Many of the romantic nostalgic tropes can be identified in modern fiction.

Thus, in modernist fiction and beyond the romantic tropes of decay, ruins, time, childhood all came to relate to universal grief and were explored further due to the contexts of late industrialization, capitalism and the horrors of the First World War. Nostalgic imagery in modern fiction evokes this sense of meaninglessness or death, and at the same time celebrates life. Often there is resonance of the astronomical images (as seen in romantic poetry) or temporal indicators that contrasts our personal death with how life goes on without us. Yvonne, in Malcolm Lowry's Under the Volcano (1947), has such a revelation:

And the earth itself still turning on its axis and revolving around that sun, the sun revolving around the luminous wheel of this galaxy, the countless unmeasured jeweled wheels of countless unmeasured galaxies turning, turning, majestically, into infinity, into eternity, through all of which all life ran on - all this, long after she herself was dead, men would still be reading in the night sky, and as the earth turned through those distant seasons, and they watched the constellations still rising, culminating, setting, to rise again [...] (Lowry 1963: 323)

The concept of individual annihilation is greatly contrasted with life, the universe, and the ever changing cycle of life. Within the cyclic motifs, this concept of personal death becomes a radical contrast. At first glance, Yvonne's real death might not seem to communicate this idea since it is almost celebratory:

And leaving the burning dream Yvonne felt herself suddenly gathered upwards and borne towards the stars, through eddies of stars scattering aloft with ever wider circlings like rings on water, among which now appeared, like a flock of diamond birds flying softly and steadily towards Orion, the Pleiades... (Lowry 1963: 337)

This passage is highly nostalgic. First, of course, because of the way the paragraph embraces many of the images of nostalgia: references to the astronomic and mythological, the 
idea of time passing, and the sense of idealization. More so, death here, as envisioned by Yvonne (or Lowry) as something peaceful, is a return to the origins of the world. This sentiment does echo Freud's ideas about the death wish as some suspect longing for a natural state, or becoming once again part of the zodiac of the universe. The word "envision" is crucial since we have to separate Yvonne's factual death from her emotions about her own.

One crucial element of nostalgia and nostalgic mood is undeniably the time arrow: the irreversibility of time and the fading of all stable molecules around us, whether that is a sand castle, a human life, or the universe. Most of the nostalgic tropes owe something to the teleological aspect of time, a matter which fundamentally causes the pain and melancholia of the nostalgia.

The famous dichotomy of clock time and inner time (Bergsonian duration) has proven a common strategy to exploit the teleological aspects of nostalgia. The occurrence of time markers, flagging clock time as an impatient but steady beat towards decay and death, are common enough. The most famous example is the use of clock time in Woolf's Mrs Dalloway (1925) where the recurring sound from Big Ben constantly reminds the reader of the time arrow, and this, in turn, becomes a huge contrast to the subjective Bergsonian time of the characters which enables a temporality that fights against clock time. Time markers can thus be as simple as a reminder of clocks, as in Mrs Dalloway, or time experienced by its characters such as Dick Diver "listening to time" while "listening to the buzz of the electric clock [...]" (Fitzgerald 1955: 213). Time markers can also be more grammatical as an extended use of time indicators such as tense inflections and time adverbials.

Likewise, the idea of the ruin as a prime symbol of decay and past time is a potent one. Nowhere is this stronger than in the notion of the sand castle that so quickly deteriorates into a sand ruin. A fine example of the use of ruin imagery can be found in the first chapter of Under the Volcano where we are thrown into an atmosphere of decay and ruins, a chapter which forms the spring board for past times since it is the last segment of the story with feelings of remembrance and forgetfulness for a day exactly one year before. M. Laurelle walks around "deserted swimming pools", "dead tennis courts", a sleeping platform, "a faded blue Ford, a total wreck". The desolation is further enhanced by "small, black, ugly birds", "[w]indy shadows [that] swept the pavements" and a "crash of thunder" which twitches off the street lights (Lowry 1963: 10, 11, 13, 19, 19, 29, 30). These ruins, gloomy images, and sounds contain the sentiment of change and something lost but they also illustrate metaphorically the havoc of a man, Geoffrey Firmin. The perception of this angst reaches a climax in two images: a deserted plough and an abandoned palace. The image of the plough, more emblematic in its presentation as a silhouette, 
clearly indicates the decayed spirit of the consul through its allusion to a human form: "there was a row of dead trees. An abandoned plough, silhouetted against the sky, raised its arms to heaven in mute supplication [...]" (Lowry 1963: 15). The abandoned palace creates an ever stronger sense of decay through the heavy use of negative adjectives and a prose stimulating primarily the olfactory senses:

The broken pink pillars, in the half-light, might have been waiting to fall down on him: the pool, covered with green scum, its steps torn away and hanging by one rotting clamp, to close over his head. The shattered evil -smelling chapel, overgrown with weeds, the crumbling walls, splashed with urine, on which scorpions lurked - wrecked entablature, sad archivolt, slippery stones covered with excreta - this place, where love had once brooded, seemed part of a nightmare. (Lowry 1963: 20)

The insertion of the positive, past love, is an effective juxtaposition and accentuation to the decay which becomes a more pleasant alternative to the present. It reinforces the nostalgia in creating alternatives to the unpleasant present. The use of binaries once more focuses on the decay and makes it darker and stronger. Throughout the first chapter of Under the Volcano, we find numerous openings to idealized and mythological places that work in contradiction to the abashed present. There are direct allusions to the "Earthly Paradise" (Lowry 1963: 16) or more implicit references to biblical events, identified by Chris Ackerley and Lawrence J. Clipper (Ackerley 1984: 52), such as the allusion to psalm 8:3-5: "What, after all, was a Consul that one was mindful of him?” (Lowry 1963: 35) Further biblical allusions are the etymology of the consul's name, Geoffrey (“God's peace” or "beloved of God”) (Ackerley 1984: 32), and the constant references to him as Adam, the connections to Swedenborg, and Dorés painting of Dante's paradise (Lowry 1963: 11). Hints of more mythological places are also found in the references to the seven daughters of Atlas and Pleione, the old Aztec myths, in the sentence "Nights of the Culmination of the Pleiades!" (Lowry 1963: 35), and references to Atlantis through a film (Lowry 1963: 21). The consul's high regard for William Blackstone, a man who left the Puritans in Massachusetts in 1635 to live close to the Indians and nature, seems to represent this general idea of the simplicity of life and man's return to nature, "away from the people with ideas" (Lowry 1963: 96). Together with a multitude of references to the Earthly Paradise or other mythological spaces, as well as more historical nostalgias prior to the age of modernity, these idealized spaces provide both a sense of longing and a contrast to the present tensions of a looming world war.

Nostalgia evoked through the use of childhood is generally achieved by addressing the world of childhood as an alternative to the present. This is done either through the use of an 
idealized space or time, by reinforcing its past character, or by using common symbols or representations of childhood that force the reader into the sensations of his own past childhood.

We can observe how the notion of an idealized childhood is conveyed through the enhanced, imaginative places and narration of the children's books of the first half of the 1900s, something Fay Sampson acknowledges in "Childhood and Twentieth-Century Children's Literature" (2000). Literary childhood is always a memory, always constructed, and perhaps idealized. Childhood itself is an idealized space, reflected upon with nostalgia that affects the narration and the style of the prose. Sampson primarily studies the way another type of rhapsodized places exists within these already highly idealized settings, such as Peter Pan's Never -Never Land, the Secret Garden in the novel of the same name, or the top of the forest in the Pooh stories (Sampson 2000: 62).

Sometimes childhood seems to be an excuse for a resistance to progress and modernity. "Wind in the Willows," writes Sampson, "is not really a children's book, but a middle class adult's nostalgia for a rural idyll, a flight from the industrial and proletarian present" (Sampson 2000: 62). The concept of idealized childhood seems, thus, closely related to that of the entropic time in which childhood is the golden age that is bound to be destroyed by time.

The impossibility for these spaces to exist in real life, or the impossibility of a return to childhood, is cleverly communicated through the name of this space in J. M. Barrie's Peter Pan (1911), "Never Never Land." The first line in Peter Pan, "All children, except one, grow up" (Barrie 2007: 9) confirms this where the "one" is an imaginary hope, a nostalgic force against progress - a hope in vain since the reality is so firmly described by the simplicity of "grow up." The nostalgic entropy is further enforced on the first page when Mrs. Darling exclaims why the children cannot remain the same forever and through Wendy's introspective thought "Two is the beginning of the end" (Barrie 2007: 9). The sadness of lost childhood, as represented by Neverland, is forcefully explained by the narrator: "On these magic shores children at play are for ever beaching their coracles. We too have been there; we can still hear the sound of the surf, though we shall land no more" (Barrie 2007: 14). The idealized Neverland is not only rosy in its description of childhood, but also in the typical manner its gaming qualities of "savages and lonely lairs" (Barrie 2007: 13) are contrasted with "chocolate-pudding day" and "three-pence for pulling out your tooth yourself [...]" (Barrie 2007: 14). For the adult these childhood memories, although not that attractive at the time, is now part of the idealization of childhood.

Returning once again to Under the Volcano, we confront our childhood, together with the protagonist, through an image used as a symbol for childhood: The Ferris wheel. The Ferris wheel as a traditional symbol tends to illustrate, based on its circular shape and its movement, the 
human heart, the circle of life with its ups and downs. A Ferris wheel is something that we associate mainly with childhood or a childhood experience of awe and fascination. It is not only the actual image of the Ferris wheel that comes to mind, but also other senses associated with it such as the blinking lights, the noise of the people in it, and perhaps a melody being played. In a wider sense it has become the main staple of the amusement park with all those associations. It carries both the fascination for our own past childhood and the magic we have lost with it.

In Under the Volcano we first encounter the Ferris wheel through the focalization of M. Laurelle:

[...] the slowly revolving Ferris wheel, already lit up, in the square of Quauhnahuac; he thought he could distinguish the sound of human laughter rising from its bright gondolas and, again, that faint intoxication of voices singing, diminishing, dying in the wind, inaudible finally. (Lowry 1963: 16)

It is important to note how crucial the sounds are in this image, and it is basically the sounds of the dying voices that represent, or enhance, the sense of lost childhood. In the end of chapter one, commencing the long analepsis which will be the body of the text, the Ferris wheel becomes the emblem of recreating the past through its reversed motion: "Over the town, in the dark tempestuous night, backwards revolved the luminous wheel” (Lowry 1963: 47).

For the consul the Ferris wheel will more explicitly come to represent that lost childhood through his comparison of it to that of "an enormously magnified child's structure of girders and angle brackets, nuts and bolts, in Meccano [...]” (Lowry 1963: 221).

Somewhat later he experiences something of a moment of truth when he enters, what he refers to as "a little confession box" in the "huge looping-the-loop machine [...]" (Lowry 1963: 224-25). There seems to be a kind of desperation, not only to clear the mind of his spinning associations but also to regain possession of his own past, a project doomed to fail in this "monster" (Lowry 1963: 225). But the encounter with the fair and all its air of nostalgia definitely charges him with revelations of the essence of nostalgia. The merriment of the first stage of nostalgia suddenly alters into the later tragic sense of having lost something; a process that simulates that of the nostalgic experience:

At the same time, as though a cloud had come over the sun, the aspect of the fair had completely altered for him. The merry grinding of the roller skates, the cheerful if ironic music, the cries of the little children on their goose-necked steeds, the procession of queer pictures - all this had suddenly become transcendentally awful and tragic, distant, transmuted, as it were some final impression on the senses of what the earth was like, carried over into an obscure region of death, a gathering thunder of immediatable sorrow [...] (Lowry 1963: 218) 
The tragic aspect of nostalgia and the stages of the nostalgic reaction are forcefully transported into the reader through the brilliant metaphor of the cloud obscuring the sun, and this creates a strong sensual experience connected to that of the "goose-necked steeds" later. It is a scene that carries both the remembrance and its representation through the enumeration of what the fair actually displays. The melancholia, or in this case the tragedy, arise out of the awareness of this lostness.

It is not only the contexts of childhood that carry nostalgic possibilities but also the general appreciation of youth as a stage of physical perfection and opportunities. Nostalgia is evoked when youthfulness is contrasted with indications of aging and human decay, either explicitly through the narrative or implicitly through the private awareness of this decay.

Fitzgerald's Tender is the Night $(1934 / 1951)$ is a book that predominantly uses the idea of youth as a nostalgia for its main characters. Dick Diver's fascination for Nicole is primarily her air of youth: "She smiled, a moving childish smile that was like all the lost youth in the world" (Fitzgerald 1955: 28). The structure of the novel becomes a celebration of youth that changes into a loss of youth, a progress intensified by the imagery of the book and how the characters are scourged by the idea of youth.1 Youth not only equals strength, but also female beauty, and the loss of youth is clearly signified by how the characters experience this loss of beauty. Nicole's years slip "away by clock and calendar and birthday, with the added poignance of her perishable beauty" (Fitzgerald 1955: 228). In reality, the human body equals that of any other fabric and will inevitably become a ruin.

The arresting image of youth, and the world through youth, makes identification between the reader's own youth and the fictive youth possible. The descriptions of youth, especially in Fitzgerald's works, tend toward an idealization of youth, as in the description of young Judy Jones in "Winter Dreams" (1922):

She was arrestingly beautiful. The color in her cheeks was centered like the color in a picture-it was not a "high" color, but a sort of fluctuating and feverish warmth, so shaded that it seemed at any moment it would recede and disappear. This color and the mobility of her mouth gave a continual impression of flux, of intense life, of passionate vitality-balanced only partially by the sad luxury of her eyes. (Fitzgerald and West 2007: 49)

It is not only the beauty in Judy Jones, but more so the celebration of her youthfulness in the use of words associated with main characteristics of youth such as "flux," "intense life," and "passionate vitality." Not only does Judy Jones embrace the ideal of youth in her physical appearance, but also in her activities. She is later spotted by Dexter as she is driving a racing

\footnotetext{
${ }^{1}$ This refers to the structure of the 1951 edition.
} 
motor boat, a potent image of "white streamers of cleft water [that] rolled themselves out behind it" before it "was sweeping in an immense and purposeless circle of spray round and round in the middle of the lake" (Fitzgerald and West 2007: 50). Judy Jones then, after acquainting herself with Dexter, jumps into the water swimming "with a sinuous crawl" where her arms "burned to butternut, moved sinuously among the dull platinum ripples, elbow appearing first, casting the forearm back with a cadence of falling water, then reaching out and down, stabbing a path ahead" (Fitzgerald and West 2007: 51). The detail of the crawl, an almost microscopic study of her decisive "stabbing," creates the impression of watching her in slow-motion. No wonder Dexter has something of a nervous breakdown in the end when he realizes that Judy Jones is no longer representing the potent beauty of his youth, for when he is describing her he is, in fact, describing his own youth:

The dream was gone. Something had been taken from him. In a sort of panic he pushed the palms of his hands into his eyes and tried to bring up a picture of the waters lapping on Sherry Island and the moonlit verandah, and gingham on the golf links and the dry sun and the gold color of her neck's soft down. And her mouth damp to his kisses and her eyes plaintive with melancholy and her freshness like new fine linen in the morning. Why, these things were no longer in the world! They had existed and they existed no longer. (Fitzgerald and West 2007: 65)

Dexter's realization of time's absolute progress forward necessitates a creation of nostalgic episodes that come to represent his own youth. These images are tied together with repeated "and" in order to emphasize the breath-taking character they possess. Youth is juxtaposed with decay and death.

Nostalgia is inevitably tied to a personal teleological, entropic idea that the progress of our lives must end in death. The sense of the nostalgic death mood is much the one of carpe diem. Nostalgia is not fear of the present: it is fear of death. Our longing back into the past corresponds with our futile endeavours to slow down the life process or retard our eschatology. Linda Hutcheon clearly distinguishes this aspect of nostalgia as "an attempt to defy the end, to evade teleology" (Hutcheon 2000: 196). To travel back into our subjective time is an uprising against mechanical clock time. Of course, the futility of the project unfolds when we discover that it does not help; this is the bitter pill of the nostalgic experience. 


\section{ACKNOWLEDGEMENTS}

All articles published in the issue are the revised texts based on lectures delivered at the $4^{\text {th }}$ International Interdisciplinary Memory Conference in Gdansk "Memory, Melancholy and Nostalgia" (17-18 Semptember, 2015).

\section{SUMMARY}

\section{"Our flame, the will-o'-the-wisp that dances in a few eyes, is soon to be blown out and all will fade" - Modern Literary Nostalgia as Death Mood}

This article argues that there is a difference between nostalgic emotion and nostalgic mood and that the latter one often is a result of nostalgia's inevitable link to death, entropy and teleology. It examines how nostalgic tropes, such as ruins, childhood, youth, astronomical representations, and subjective time (duration), inherited from the romantic poetry function as, and create, nostalgic death moods and retardations of eschatology in modernist fiction.

\section{KEYWORDS}

Nostalgia, modernist fiction, modernism, death, emotions, mood, entropy, teleology, childhood, youth, duration, Bergson, ruins, astronomy 


\section{BIBLIOGRAPHY}

Ackerley, Chris and Lawrence J. Clipper. 1984. A Companion to Under the Volcano. Vancouver: University of British Colombia Press.

Barrie, J. M. 2007. Peter Pan and Peter Pan in Kensington Gardens. Ware: Wordsworth Editions Limited. Original edition, 1922, 1902.

Colley, Ann C. 1998. Nostalgia and Recollection in Victorian Culture. Basingstoke: Macmillan.

Fitzgerald, F. Scott. 1955. Tender is the Night. London: Penguin Books. Original edition, 1934.

Fitzgerald, F. Scott, and James L. W. West. 2007. All the Sad Young Men. Cambridge: Cambridge University Press. Original edition, 1926.

Freud, Sigmund. 1955. Beyond the Pleasure Principle, Group Psychology, and Other Works. James Strachey, Anna Freud, Alix Strachey and Alan Tyson, transl. London: Hogarth Press.

Hart, James G. 1973. "Toward a Phenomenology of Nostalgia." Man and World: An International Philosophical Review 6 (4):397-420.

Hutcheon, Linda. 2000. "Irony, Nostalgia, and the Postmodern." Methods for the Study of Literature as Cultural Memory, Studies in Comparative Literature 30:189-207.

Lowry, Malcolm. 1963. Under the Volcano. Middlesex: Penguin Books. Original edition, 1947.

Sampson, Fay. 2000. "Childhood and Twentieth-Century Children's Literature." In Childhood

Studies: A Reader in Perspectives of Childhood, edited by Jean Mills and Richard W. Mills, 61-76. New York: Routledge.

Santesso, Aaron. 2006. A Careful Longing: The Poetics and Problems of Nostalgia. Newark, N.J.: University of Delaware Press.

Thayer, Robert E. 1989. The Biopsychology of Mood and Arousal. New York ; Oxford: Oxford University Press.

Woolf, Virginia. 2000. The Waves. Hertfordshire: Wordsworth Editions Limited. Original edition, 1931. 
